\title{
Epitaxial Silicon Carbide Films Grown by New Method of Replacement of Atoms on the Surface of High-resistivity (111) Oriented Silicon
}

\author{
Dina I. Bakranova ${ }^{1}$, Sergey A. Kukushkin ${ }^{2, a}$, Kair Kh. Nussupov ${ }^{1}$, Andrey V. Osipov ${ }^{2}$, Nurzhan B. Beisenkhanov ${ }^{1, a}$ \\ ${ }_{1}^{1}$ Kazakh-British Technical University, Kazakhstan \\ 2 Institute for Problems of Mechanical Engineering, Russia
}

\begin{abstract}
The nanolayers of single crystal $\mathrm{SiC}$ were grown on the surface of a high-resistance n-type silicon substrates by replacement of the atoms in the crystal lattice of silicon on the carbon atoms at the temperatures of 1250 , $1330{ }^{\circ} \mathrm{C}$ and $\mathrm{CO}$ gas pressures $264,395 \mathrm{~Pa}$, respectively. The formation of crystalline $\beta$-SiC phase in films by electron diffraction and Raman spectroscopy techniques was shown. The SiC films are epitaxial and do not contain twins on the surface. By Atomic Force Microscopy is shown that two set of SiC films have pyramidal and step-like structure of the surface with clear-cut fragmentation of grains with sizes between 100 and $200 \mathrm{~nm}$, and this is due to the composition of carbon and silicon atoms in the layer. Two set of $\mathrm{SiC}$ films have a granular surface structure with indistinct grain fragmentation. The influence of synthesis condition on the microstructure of film surface is discussed.
\end{abstract}

\section{Introduction}

In a series of papers, generalized in review [1], it has been developed theoretically and experimentally implemented a new method of growth of high quality thin $\mathrm{SiC}$ films on Si. The method consists of replacing part of the atoms of the matrix of silicon on the carbon atoms to form molecules of silicon carbide. The process of replacement occurs gradually without destroying the crystal structure of silicon. Moreover, the "old" original crystalline structure of the silicon matrix defines the orientation of the film, while using conventional techniques only the surface of the silicon substrate defines the film orientation. According [1] the process of silicon atoms replacement on the carbon atoms can be realized by using such chemical reaction as $2 \mathrm{Si}+\mathrm{CO}=$ $\mathrm{SiC}+\mathrm{SiO}$.

It is known [2] that $\mathrm{SiC}$ has more than 170 different polytypes. The most common forms are cubic (3C-SiC), as well as hexagonal $4 \mathrm{H}, 6 \mathrm{H}(\alpha-\mathrm{SiC})$ [2-5]. Raman spectroscopy is an efficient and non-destructive technique which may be used to identify the structure of the $\mathrm{SiC}$ polytype. In the case of $3 \mathrm{C}-\mathrm{SiC}$ typically two strong Raman peaks are observed: at $972 \mathrm{~cm}^{-1}$, corresponding to the peak of longitudinal optical (LO) phonons; at 796 $\mathrm{cm}^{-1}$, corresponding to the peak of transverse optical (TO) phonons [5]. Hexagonal modes for $6 \mathrm{H}-\mathrm{SiC}$ are indicated by splitting the TO mode into three peaks: $\mathrm{TO}_{2}$ at 767 $\mathrm{cm}^{-1}$ and $789 \mathrm{~cm}^{-1}, \mathrm{TO}_{1}$ at $797 \mathrm{~cm}^{-1}, \mathrm{LO}_{1}$ at $965 \mathrm{~cm}^{-1}$ [5].

In this work, using Raman spectroscopy, electron microscopy and Atomic Force Microscopy the nanolayers of single crystal $\mathrm{SiC}$ grown by this method, have been investigated.

\section{Experimental}

The nanolayers of single crystal $\mathrm{SiC}$ were grown on the surface of a high-resistance n-type silicon substrates. The thickness of the original (111) oriented silicon substrates was about 1300 microns. Before synthesis, the surface of silicon wafers were ground, polished and specially treated to obtain a smooth mirror surface. SiC films were synthesized in a special installation, developed by the authors [6]. The synthesis was carried out under the following conditions. Two series of samples, marked № 1 and № 2, were grown at the temperature of $1250{ }^{\circ} \mathrm{C}$ and at pressure of $264 \mathrm{~Pa}$ in the atmosphere of $\mathrm{CO}$. The growth time of these samples was $15 \mathrm{~min}$. Two other series of films, marked № 3 and № 4, were synthesized for 7 minutes at the temperature of $1330{ }^{\circ} \mathrm{C}$ and at pressure of $395 \mathrm{~Pa}$ in the atmosphere of $\mathrm{CO}$.

The composition of the films was investigated by Raman spectroscopy using a confocal Raman microscope Alpha 300R (WITec, Germany). The microstructure of the surface of the films was studied using the atomic force microscope JSM 5200 (Jeol, Japan) by semi-contact (AFM AC) method. Resolution of the microscope on a plane is $0.14 \mathrm{~nm}$ and vertical resolution $-0.01 \mathrm{~nm}$.

\section{Results}

Figure 1 presents the Raman spectra of the crystalline silicon carbide films on silicon substrates (samples № 1 (a), № 2 (b), № 3 (c) and № 4 (d)), synthesized by replacement of the atoms in the crystal lattice of silicon.

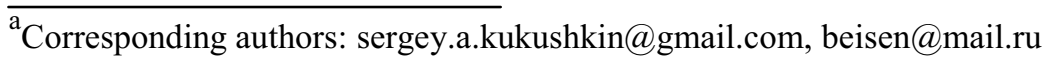


The spectra show the presence of first and second order transverse acoustical phonon (2TA) peaks from the crystalline $\mathrm{Si}$ substrate [7] at 519.7 and $303.3 \mathrm{~cm}^{-1}$, respectively. A clear peak due to the $\mathrm{Si}$ second order features [7] appearing at $971.4 \mathrm{~cm}^{-1}$ is also presented.

Figure la - d shows that in the Raman spectra of the SiC films № 1 and № 2, synthesized at a temperature of $1250{ }^{\circ} \mathrm{C}$ and a pressure of $264 \mathrm{~Pa}$, and the $\mathrm{SiC}$ films № 3 и № 4, synthesized at a temperature of $1330{ }^{\circ} \mathrm{C}$ and a

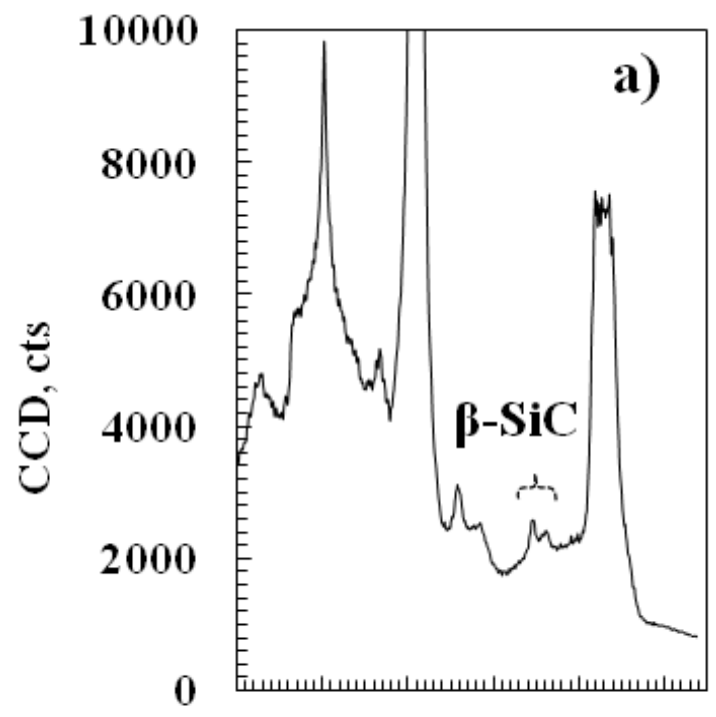

1003005007009001100

Raman shift, $\mathrm{cm}^{-1}$

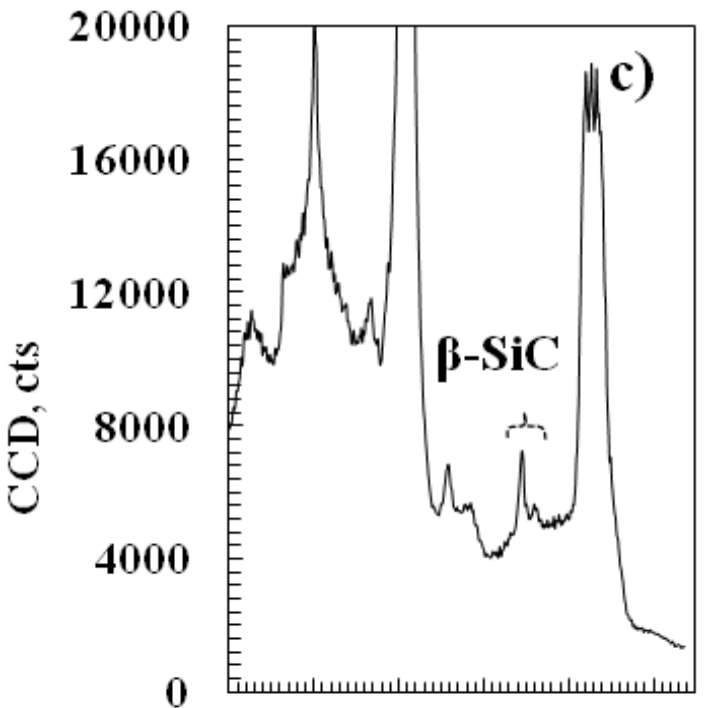

1003005007009001100

Raman shift, $\mathrm{cm}^{-1}$ pressure of $395 \mathrm{~Pa}$, there are broad peaks at $730-860$ $\mathrm{cm}^{-1}$ centered in the TO mode of $\beta-\mathrm{SiC}$ at $\sim 796 \mathrm{~cm}^{-1}[8]$ consisting of two components with maxima at $792.6 \pm$ $0.3 \mathrm{~cm}^{-1}$ and $822.7 \pm 1.1 \mathrm{~cm}^{-1}$ (Table 1). It is evident that the greatest value of the amplitude of the peaks characteristic of the films of SiC № 2 and № 3.

The LO mode of $\beta-\mathrm{SiC}$ at $969 \mathrm{~cm}^{-1}$ is impossible to identify due to the superimposed Si-second-order Raman background.

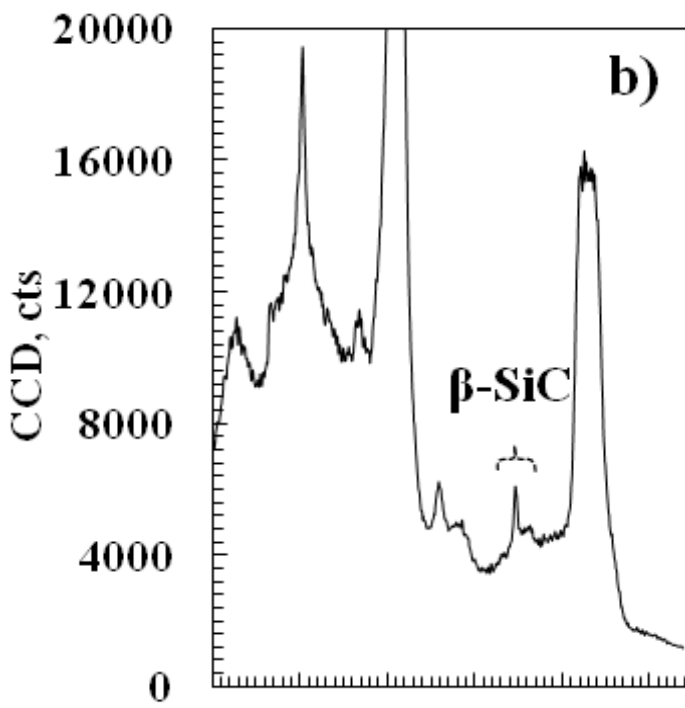

1003005007009001100 Raman shift, $\mathrm{cm}^{-1}$

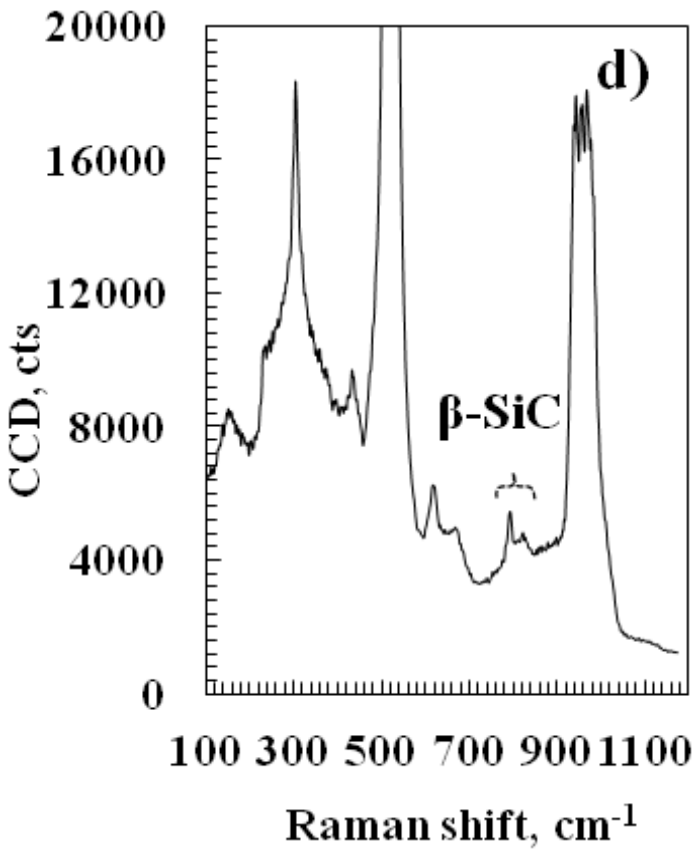

Figure 1. Raman spectra of crystalline SiC films on silicon substrates (samples № 1 (a), № 2 (b), № 3 (c) and № 4 (d)), synthesized by replacement of atoms in the crystal lattice of silicon

Table 1. The position of the maxima of two components of $\beta$-SiC TO mode in the Raman spectrum

\begin{tabular}{|l|c|c|c|c|c|c|c|c|}
\hline Option & \multicolumn{2}{|c|}{ SiC film № 1 } & \multicolumn{2}{c|}{ SiC film № 2 } & \multicolumn{2}{c|}{ SiC film № 3 } & \multicolumn{2}{c|}{ SiC film № 4 } \\
\hline Position of maxima, $\mathrm{cm}^{-1}$ & 791.8 & 822.7 & 791.8 & 826.1 & 792.4 & 821.6 & 792.9 & 822.7 \\
\hline
\end{tabular}


Studies by Atomic Force Microscopy of the surface microstructure of the film № 1 in areas with dimensions of $500 \times 500 \mathrm{~nm}$ (Figure 2a) and $200 \times 200 \mathrm{~nm}$ (Figure $2 b)$ show that the film surface after synthesis has a pyramidal structure and is composed of large crystals with sizes $\sim 100 \times 100 \mathrm{~nm}$, has clear-cut fragmentation of grains and height variations within $19 \mathrm{~nm}$. Protruding portions of the surface have bright color, low surface areas, from which height countdown begins, have a dark color.

The surface of the film № 2 (Figure 2c, d) at similar areas has a step-like structure, variation of height up to 38
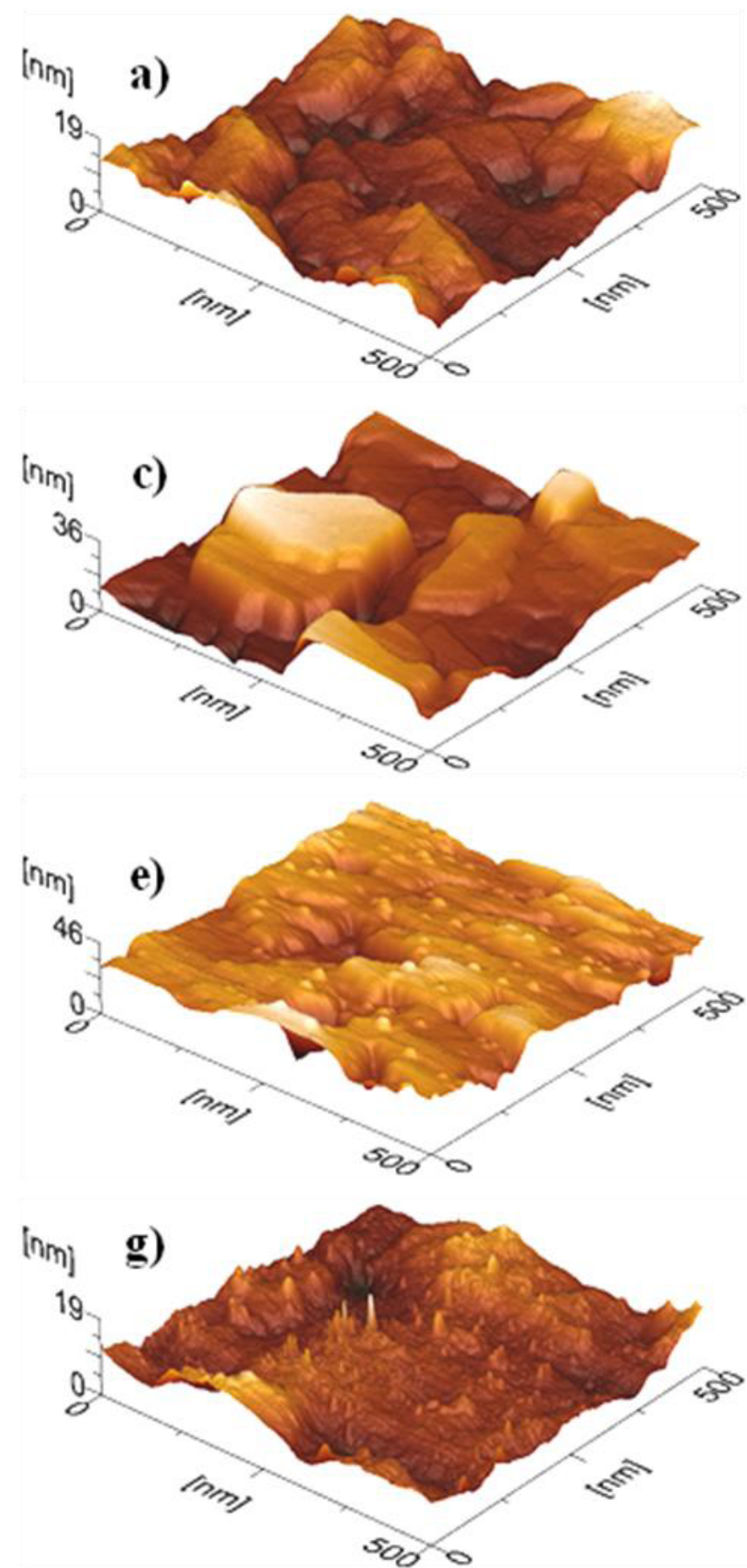

$\mathrm{nm}$ and more clear-cut fragmentation of large crystals with sizes of about $200 \times 150 \mathrm{~nm}$. SiC films № 3 (Figure 2e, f) and № 4 (Figure $2 \mathrm{~g}, \mathrm{~h}$ ) have a granular surface structure with variations of height up to $46 \mathrm{~nm}$ and $19 \mathrm{~nm}$, respectively, with indistinct grain fragmentation.

In general, it is seen that the films № 1 and № 2 have a similar structure with a distinct fragmentation of the grains on the surface and different from films № 3 and № 4 having insufficient grain fragmentation. This may be due to excessive content of carbon atoms $[9,10]$ in the films № 3 and 4 due to the higher synthesis temperature and a high pressure of $\mathrm{CO}$ gas.
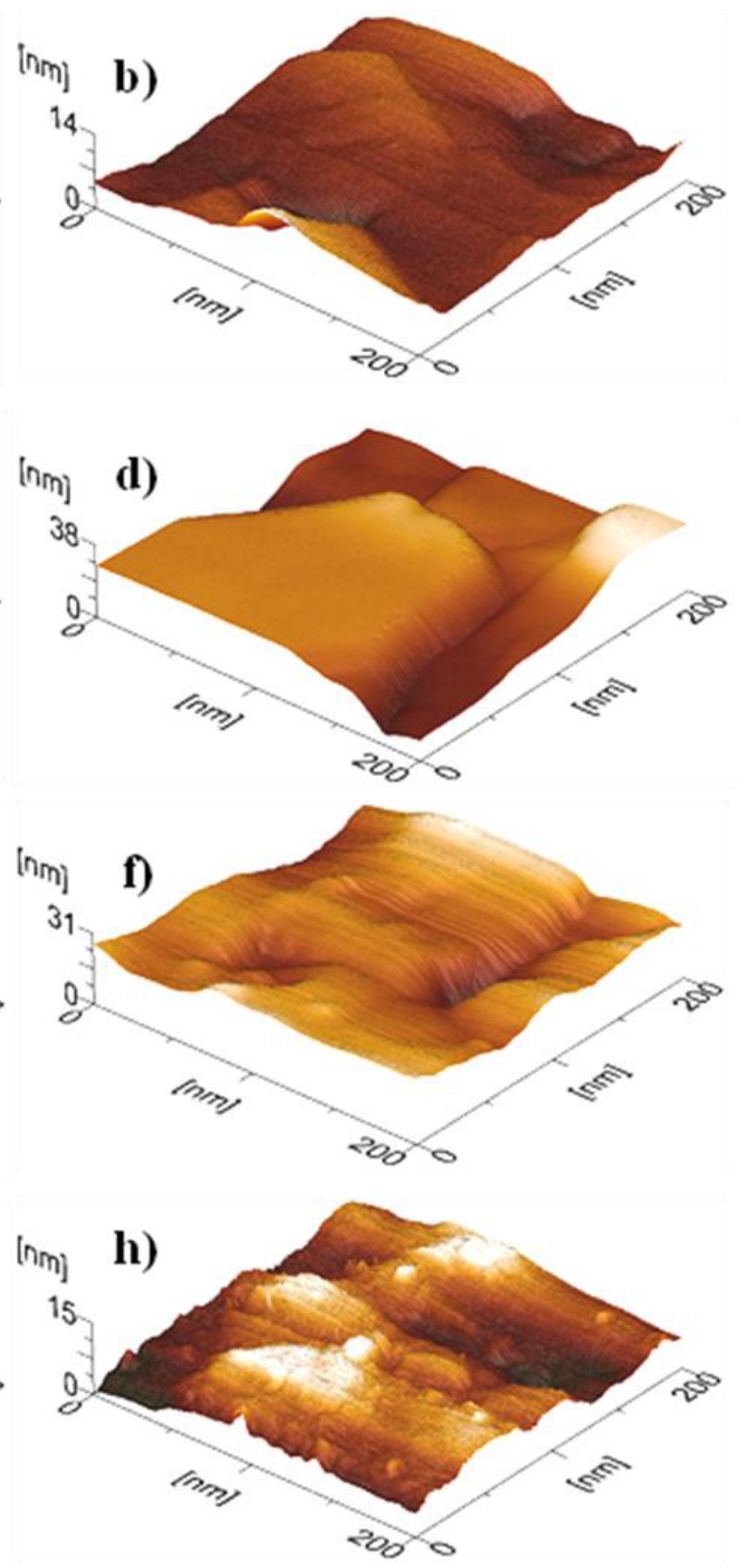

Figure 2. Atomic Force Microscopy of the surface microstructure of the SiC films № 1(a,b), № 2(c,d), № 3(e,f), № 4(g,h), in areas with dimensions of $500 \times 500 \mathrm{~nm}(\mathrm{a}, \mathrm{c}, \mathrm{e}, \mathrm{g})$ and $200 \times 200 \mathrm{~nm}(\mathrm{~b}, \mathrm{~d}, \mathrm{f}, \mathrm{h})$ 
Figure 3 shows the electron diffraction patterns of the SiC films of samples № 1, № 2, № 3 and № 4, measured in the $<110>$ zone axis projection.

Point reflexes of electron diffraction patterns clearly indicate that the (111) oriented $3 \mathrm{C}-\mathrm{SiC}$ layer lies on the surfaces of Si samples № 1, № 2, № 3 and № 4, and the direction [111] of this layer perpendicular to the substrate surface. It is also evident from electron diffraction patterns that the $\mathrm{SiC}$ films are epitaxial and do not contain twins on the surface.
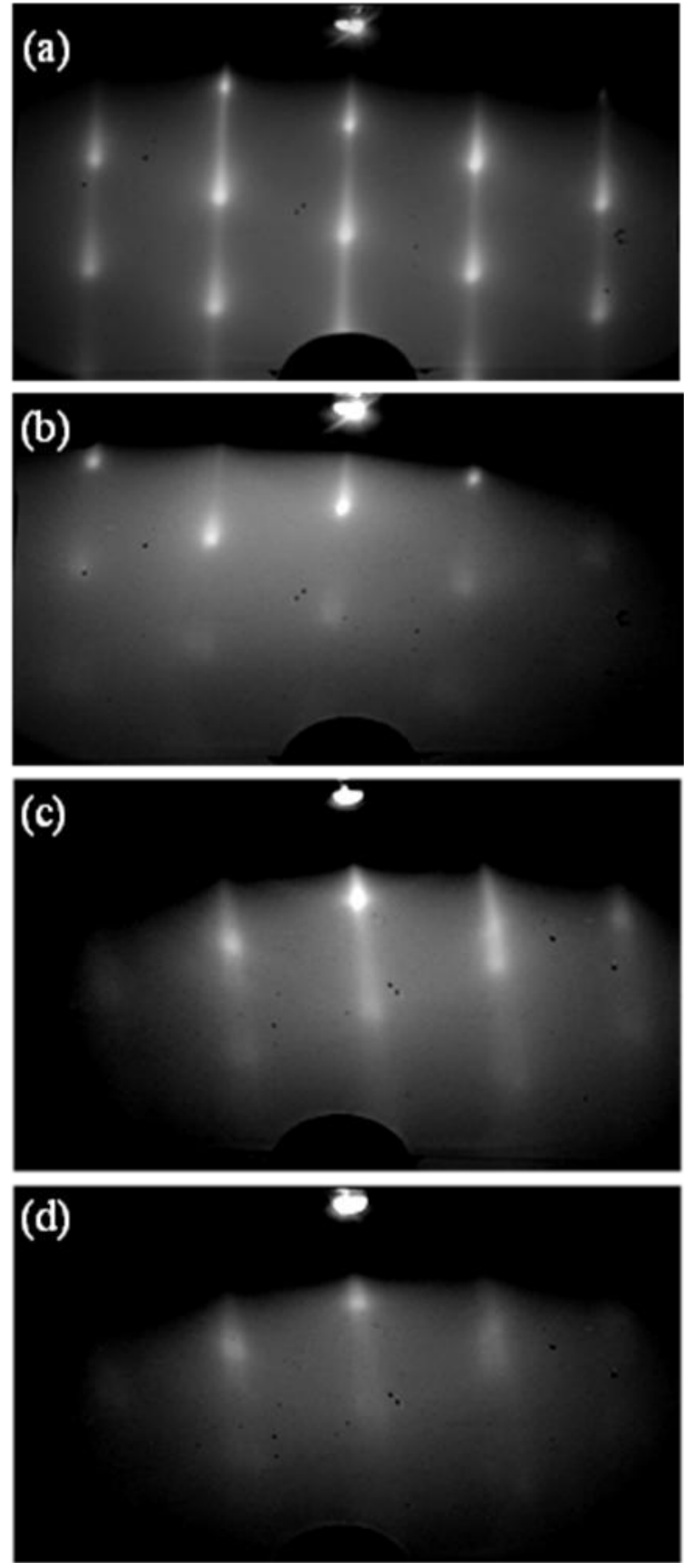

Figure 3. Reflection electron diffraction patterns of the $\mathrm{SiC}$ films recorded in the $\langle 110\rangle$ zone axis projection for samples № 1 (a), № 2 (b), № 3 (c), № 4 (d)

\section{Conclusion}

The nanolayers of single crystal $\mathrm{SiC}$ were grown on the surface of a high-resistance n-type silicon substrates by replacement of the atoms in the crystal lattice of silicon on the carbon atoms.

The formation of crystalline $\beta$-SiC phase in films synthesized at the temperature of $1250{ }^{\circ} \mathrm{C}$ and the pressure of $\mathrm{CO}$ gas $264 \mathrm{~Pa}$ or $1330{ }^{\circ} \mathrm{C}, 395 \mathrm{~Pa}$, were shown. The (111) oriented $3 \mathrm{C}-\mathrm{SiC}$ films on the (111) oriented silicon substrates are epitaxial and do not contain twins on the surface.

It is shown that the films № 1 and № 2 have a similar pyramidal or step-like structure of the surface with variations of height up to 19 and $38 \mathrm{~nm}$, respectively, and with clear-cut fragmentation of grains with sizes between 100 and $200 \mathrm{~nm}$, and this is due to the composition of carbon and silicon atoms in the layer. SiC films № 3 and № 4 have a granular surface structure with indistinct grain fragmentation and this is due to high content of carbon atoms in the films due to the higher synthesis temperature and a high pressure of $\mathrm{CO}$ gas.

\section{Acknowledgments}

Authors would like to acknowledge Redkov A.A. for help in measuring the Raman spectra.

\section{References}

1. S.A. Kukushkin, A.V. Osipov, J. of Phys. D: Appl. Phys. 47, 313001 (2014)

2. S. Nakashima, H. Harima, Phys. Stat. Sol. A, 162, 39 (1997)

3. M.J. Pelletier, Analytical applications of Raman spectroscopy, Blackwell Science, UK (1999)

4. S. Nakashima, K. Tahara, Phys. Rev., B, 40, 6339 (1989)

5. S. Nakashima, H. Harima, T. Tomita, T. Suemoto, Phys. Rev. B, 62, 16605 (2000)

6. S.A. Kukushkin, A.V. Osipov, N.A. Feoktistov, Physics of the Solid State 56 (8), 1507 (2014)

7. L. Yu, S. Intarasiri, T. Kamwanna, S.Singkarat, In book: Ion beam applications in surface and bulk modification of insulators. Austria, Vienna: IAEATECDOC-1607. 63 (2008)

8. T. Zorba, D.I. Siapkas, C.C. Katsidis, Microelectron. Eng. 28, 229 (1995)

9. K.Kh. Nussupov, N.B. Beisenkhanov. In book: Silicon Carbide - Materials, Processing and Applications in Electronic Devices, Moumita Mukherjee (Ed.).. Chapter 4, InTech, 69 (2011) http://www.intechopen.com/books/silicon-carbidematerials-processing-and-applications-in-electronicdevices/the-formation-of-silicon-carbide-in-the-sicxlayers-x-0-03-1-4-formed-by-multiple-implantationof-c-

10. K.Kh. Nussupov, N.B. Beisenkhanov, I.V. Valitova, K.A. Mit', D.M. Mukhamedshina, E.A. Dmitrieva J. of Materials Science: Materials in Electronics, 19. 254 (2008) 